\title{
BULLYING: CONCEPÇÕES DOS PARTICIPANTES DE UM CURSO DE EXTENSÃO
}

Kelly Regina Conde, Camila Fernanda Dias Pavaneli, Julia Neves Ferreira, Andressa Carolina Scandelai Parra, Luciana Aparecida Nogueira da Cruz.

Universidade Estadual Paulista - UNESP, Programa de Pós Graduação em Ensino e Processos Formativos, São José do Rio Preto, SP. E-mail: kelly conde@hotmail.com

\section{RESUMO}

O bullying é um problema moral, sendo uma forma de desrespeito expressa por uma ação intencional e repetida de intimidação ou opressão, com agressões físicas e/ou verbais, sem motivações aparentes, causada por um ou mais estudantes, gerando dor, angústia, humilhação e discriminação à vítima. Esta pesquisa analisa o papel dos profissionais da educação frente a este fenômeno, investigando as concepções que possuem sobre o bullying. As respostas dos participantes do curso de extensão "Desenvolvimento Moral Infantil", oferecido pela Unesp de São José do Rio Preto, à questão "O que é bullying?" serviram como base para a análise em questão. Todos os sujeitos da pesquisa percebem o bullying como algo desrespeitoso e que causa danos às relações, mesmo que se atenham apenas a algumas características dos fenômenos. É importante, no entanto, que os profissionais da educação possuam mais conhecimentos sobre como intervir para favorecer o despertar da sensibilidade moral nos estudantes.

Palavras-chave: Moralidade, bullying, formação continuada, psicologia moral, convivência.

\section{BULLYING: PARTICIPANTS CONCEPTIONS OF AN EXTENSION COURSE}

\begin{abstract}
Bullying is a moral problem, a form of disrespect expressed by an intentional and repeated act of intimidation or oppression, with physical and / or verbal aggression without apparent motivation, caused by one or more students, causing pain, distress, humiliation and discrimination against the victim. This research analyzes the role of education professionals in this phenomenon by investigating their conceptions of bullying. The responses of participants in the extension course "Moral Development for Children", offered by Unesp in São José do Rio Preto, to the question "What is bullying?" served as basis for the mentioned analysis. All the subjects of the research perceive the bullying as something disrespectful and that causes damage to the relations, even if they are only limited to some characteristics of the phenomena. It is important, however, that educational professionals have more knowledge about how to intervene to promote the awakening of moral sensitivity in students.
\end{abstract}

Keywords: Morality; Bullying; Continuing Education; Moral Psychology; Acquaintanceship; 


\section{INTRODUÇÃO}

$\mathrm{Na}$ sociedade em que vivemos, as relações tornaram-se efêmeras, caracterizadas pelo vazio, por ausência tanto de valores quanto de sentido para a vida. Tudo o que era antes sólido aos poucos foi se liquefazendo, tornando-se efêmero, transformando nossa sociedade pósmoderna no que Zygmunt Bauman (2001) chamou de "modernidade líquida". Nesta sociedade, como salientam Ceccarelli e Patrício (2013), alguns fenômenos, que até então eram desconhecidos ou tratados como banalidades, "coisa de criança", atualmente ganharam destaque e repercussão nas grandes mídias. Sabe-se que, desde o surgimento das escolas, as hostilidades entre alunos existem; no entanto, foi apenas nos últimos anos que este fenômeno ganhou visibilidade. Nessa conjuntura, aparece recentemente o fenômeno bullying, e as instituições escolares viram-se obrigadas a atentarem-se para algo que não é novo, mas que foi colocado em evidência com a intensificação das cenas de violência entre alunos, casos de evasão escolar, notícias sobre danos físicos e psíquicos (PAVANELI, 2018). Sabendo, como salientava Piaget (1994), que o tipo e a qualidade das relações vivenciadas influenciam o desenvolvimento da moralidade, percebemos a importância do conhecimento do professor para intervir de maneira adequada na formação moral dos alunos, proporcionando momentos de reflexão que conduzam à autonomia (DEVRIES; ZAN, 1998; VINHA, 2000).

Bullying é um termo empregado para tratar um tipo de violência velada que denota falta de ética e acomete meninos e meninas de todas as classes sociais e idades (TOGNETTA, 2012). A palavra é advinda da língua inglesa bully que se refere a um tipo de personalidade que poderíamos traduzir como valentão ou briguento. Nessa perspectiva, compreendemos o bullying como uma ação intencional e repetida de intimidação, opressão, ofensa, roubo de pertences, chacota, agressões físicas e/ou verbais, sem motivações aparentes, causada por um ou mais estudante, que causa dor, angústia, exclusão, isolamento, humilhação e discriminação à vítima (MALTA et al., 2010).

Uma pesquisa realizada pela PlanInternacional, em 2009, constatou que $50 \%$ dos casos de bullying ocorrem na sala de aula. Dentre esses casos, $68 \%$ aconteceram na presença do professor, evidenciando a responsabilidade destes profissionais diante essa prática, uma vez que compartilhamos com Piaget (1932/1994) que a moral não é ensinada, mas sim construída e, para que isso ocorra de maneira adequada às nossas intenções, os sujeitos precisam refletir, tomar decisões, ter a oportunidade de construir o respeito por si e pelo próximo. Assim, as ações e a intervenção do professor poderão servir como exemplos positivos ou negativos para os alunos, sendo preciso saber os objetivos das suas intervenções, e, ao mesmo tempo, dar aos alunos a liberdade de vivenciarem as tomadas de decisões e as responsabilidades (CALIL, 2013). Essa necessidade de conhecimento no âmbito do desenvolvimento moral mostra-se crescente à medida em que os professores demonstram perceber a influência das relações estabelecidas no ambiente escolar para o bom desempenho dos alunos. Por isso, o Curso de Extensão "Desenvolvimento moral infantil", na modalidade difusão de conhecimento, oferecido em 2017 pelo Ibilce/UNESP, buscou auxiliar o entendimento dos professores da região de São José do Rio Preto sobre este tema, investigando também as concepções dos participantes sobre o bullying.

O objetivo deste estudo é investigar em que medida os professores das escolas compreendem o conceito de bullying para que possam diagnosticar e intervir em casos de possível incidência. Para atingir este objetivo, analisaremos as respostas dos participantes do curso de extensão "Desenvolvimento moral infantil" à questão "O que é bullying?". Desse modo, essa pesquisa se propõe a verificar as concepções de bullying existentes entre este público e sua relação com o conhecimento estabelecido sobre o assunto. 


\section{METODOLOGIA}

Trata-se de uma pesquisa qualitativa de análise de conteúdo (BARDIN, 2009) cujos dados foram obtidos por meio de um questionário aos participantes do Curso de Extensão "Desenvolvimento Moral Infantil", oferecido pelo departamento da Educação da Universidade Estadual Paulista, campus de São José do Rio Preto. A carga horária do curso foi de 30 horas, com encontros presenciais quinzenais e a pesquisa foi submetida à apreciação da Comissão de Ética da Faculdade de Filosofia e Ciências / Campus de Marília - UNESP, tendo sido aprovado com o parecer número 983.537. O principal objetivo do Curso de Extensão foi apresentar e proporcionar reflexões sobre as teorias do desenvolvimento moral (em especial, de Piaget e Kohlberg), abordando diversos aspectos do desenvolvimento infantil.

Os participantes foram 40 cursistas, (identificados como S1, S2... S40) com faixa etária variando de 21 a 67 anos, sendo 90,48\% mulheres e 9,52\% homens. Destes participantes, 95,24\% possuem nível superior completo, sendo 61\% em Licenciatura em Pedagogia, $11 \%$ em Letras e $9 \%$ em Psicologia; os demais tem formação variada e 4,76\% são graduandos. Além disso, mais da metade (59,52\%) possui pós-graduação completa, e $14,29 \%$ em andamento. A maioria dos respondentes é composta de professores (64,29\%); além destes, $11,90 \%$ são gestores e $14,29 \%$ atuantes em outras áreas, com 9,52\% declarando não trabalhar. O tempo de carreira dos profissionais varia de 2 a 4 anos e a maioria declara ter como religião o catolicismo (64\%).

Em relação ao instrumento, trata-se de um questionário disponibilizado na plataforma Survey Monkey, composto por questões dissertativas sobre assuntos tratados no curso de extensão, em que os conhecimentos e opiniões dos participantes foram expressos sem padrões pré-definidos. Após as questões sobre o perfil dos participantes, as questões seguintes buscavam identificar as concepções a respeito dos temas abordados pelo curso. Neste texto, analisamos as respostas a uma questão do instrumento, que se referia ao bullying.

Ao início do curso de Extensão foram fornecidas informações sobre a aplicação do questionário sobre os temas a serem abordados no decorrer do curso, bem como da utilização das informações coletadas. Em seguida, os participantes tomaram conhecimento do Termo de Consentimento Livre e Esclarecido e responderam ao questionário, utilizando os computadores da Instituição (Ibilce/UNESP).

\section{RESULTADOS}

Iniciamos as análises a partir da questão "O que é bullying?". As respostas foram variadas e as categorizamos de acordo com semelhanças encontradas nos tipos de pensamento apresentados.

Dos 40 sujeitos da pesquisa (aqui identificados como S1, S2, S3... S40), 12 (30\%) destacaram em suas respostas o desrespeito ao outro como uma das principais causas do bullying: Bullying é o não respeito pelo que é diferente. (S7)

Bullying é um comportamento não adequado de um indivíduo para com o outro, onde o desrespeito prevalece. (S10)

É o desrespeito com o próximo dando nomes, apelidos, agressões verbais, que diminua e inferiorize o outro. É intencional e repetitivo. (S14)

Uma forma de desrespeito ao próximo através de chacotas de uma determinada característica pessoal. (S23)

Piaget (1932/1994) destacou em uma de suas principais obras, "O Juízo moral na criança", duas formas diferentes de respeito que estariam diretamente relacionadas ao desenvolvimento moral da criança: o respeito mútuo que se define pela reciprocidade das relações e o respeito unilateral, pautando em relações de coação.

Diante de tais respostas, é possível considerarmos que a ausência do valor respeito, precisa ser entendida nas várias interfaces pelas quais se manifesta na escola, como violências, 
incivilidades, indisciplina, bullying, tendo como elemento comum a falta de um conteúdo moral (TOGNETTA; MARTINEZ e DAUD, 2017).

Outros 12 participantes (30\%), buscaram definir as situações de bullying enfatizando uma de suas principais características: agressões físicas e verbais intencionais que têm a intenção de ferir (desigualdade de poder físico e psicológico):

Bullying é um tipo de agressão contínua e intencional sobre um indivíduo que pode ser expressa de forma física, verbal ou psicológica (S12)

Bullying são agressões intencionais, que podem ser física, psicológica ou moral. (S16)

Bullying é uma ação continua de uma pessoa ou grupo contra uma outra pessoa que é agredida de forma física, verbal ou não verbal. (S25)

Bullying é qualquer atitude (verbal, física ou psicológica) que exponha um indivíduo e que Ihe cause algum dano, seja moral ou físico. (S36)

Essas respostas nos indicam que muitos educadores reconhecem pelo menos uma das características que determinam a violência acometida especificamente como um caso de bullying.

A terceira categoria que destacamos refere-se ao bullying relacionado a situações de humilhação, onde 6 participantes (15\%) ressaltaram tal característica:

Um ato negativo em relação ao outro, seja por humilhação psicológica ou física. Geralmente um mais forte contra o mais fraco. (S5)

Bullying é quando não se compreende que a "brincadeira" deixou de ser inofensiva e engraçadinha, humilhando e diminuindo o outro perante a sociedade. (S2O)

São atitude que visam menosprezar e humilhar outras pessoas que sejam diferente ou que não penso conforme seus valores. (S34)

Por fim, a última categoria que ressaltamos refere-se às 8 (20\%) respostas que indicam o bullying como uma forma de coação, intimidação, intolerância e constrangimento, relacionando tais aspectos à formas de agressão.

É coagir o outro pela sua diferença e fazer com, ele se sinta constrangido, tornando isso uma agressão. (S2)

É intimidar o amigo, repetidas vezes e deixar o amigo em uma situação constrangido $e$ envergonhado perante o grupo. Agressão. (S4)

Toda e qualquer atitude que envolve exclusão e intolerância em relação ao outro. (S19)

Visto que tais características são reconhecidas pelos educadores, Togneta (2015) ressalta a importância do papel do educador no auxílio do indivíduo que está sofrendo, fortalecendo-o para que não estejam mais na mira de seus agressores.

\section{DISCUSSÃO}

Como salienta Vinha $(1999$, p.20) "em cada ato o educador tem que perceber que está trabalhando a moralidade", pois suas intervenções servirão de parâmetro para as ações dos alunos, transmitindo seus valore e opiniões. Para a autora, a escola é o local, uma vez que muitas vezes a família se encontra perdida sem saber como educar moralmente. Portanto, de acordo inclusive com os documentos oficiais do Ministério da Educação, a exemplo dos Parâmetros Curriculares Nacionais - PCN's (BRASIL, 2001), cabe à escola empenhar-se na formação moral de seus alunos, lembrando que o bullying é um problema moral. É na escola que encontramos o espaço em que os alunos convivem com seus pares, na relação entre iguais, desse modo, há grande propensão de lá acontecerem incidências de bullying. Por isso, consideramos importante conhecer as concepções de alguns profissionais da educação sobre este assunto, já que estas concepções influenciarão suas ações perante as ocorrências deste fenômeno.

Diante das respostas dos participantes, observamos que todos percebem, ao menos de modo superficial, o conceito de bullying como um problema, algo que denota um rompimento das relações sociais e que é nocivo ao ambiente escolar, o que já avança em relação a uma opinião 
recorrente no senso comum de que apenas crianças "fracas" sofrem com isto e que não passa de brincadeira. Percebemos diversos aspectos do bullying presentes nas respostas dos participantes, porém nem sempre eles continham todas as características, algumas vezes delimitando apenas uma "falta de respeito", e em poucas aparecendo como uma violência propriamente dita.

Um dos aspectos que nos chamou a atenção foram respostas que, mesmo inclusas nas categorias já destacadas, fazem menção a características aparentemente físicas como possíveis causadoras de situações de bullying, desconsiderando que podem haver diversos tipos de alvo para os agressores e características diferenciadas não podem ser consideradas, isoladamente, motivo para agressões, sem considerar a personalidade destes indivíduos.

É a intolerância em relação ao diferente, é o não aceitar o outro e muitas vezes sem entender o porquê. (S6)

É a ofensa que ressalta uma característica de alguém, às vezes negativa ou não, de forma cruel e excludente. (S24)

Agressão verbal e ou física de uma pessoa para outra usando o que os diferem. (S37)

Ainda assim, consideramos importante ressaltar que, de maneira geral, a intolerância e a falta de respeito presentes nos casos de bullying são reconhecidas pelo público pesquisado, que não os valoriza mas, ao contrário, preza pelo respeito ao próximo e pela boa convivência entre pares.

\section{CONSIDERAÇÕES FINAIS}

Segundo Cunha (2000), precisamos considerar inicialmente as concepções dos profissionais da educação porque eles são mediadores na formação moral dos alunos e a maneira como estes sujeitos concebem a moralidade tem influência sobre as suas práticas educativas. Investigando as concepções sobre bullying dos participantes de um curso de extensão, observamos a preocupação que os profissionais da educação e mesmo os futuros professores possuem sobre possibilitar o desenvolvimento moral. No entanto, como já relatado em outras pesquisas sobre moralidade (MENIN, 2002; SHIMIZU, 1998), estes profissionais possuem pouco conhecimento sobre teorias psicológicas para embasar uma educação moral, muitas vezes prevalecendo opiniões do senso comum nas práticas escolares. Concordamos com Dias, Schwartz e Lisboa (2014) que é essencial uma capacitação dos profissionais envolvidos no cotidiano das escolas para que estes adotem condutas positivas, fazendo uso de normas claras e consistentes e possam oferecer suporte afetivo quando necessário, estimulando o fortalecimento de laços afetivos e do respeito mútuo.

Com tudo isso, ressaltamos a necessidade de investimento contínuo na formação de professores para a construção de uma educação voltada para o desenvolvimento integral dos alunos, o que significa o favorecimento tanto de seu desenvolvimento cognitivo quanto do seu desenvolvimento social e moral. Não basta apenas perceber a existência de um problema, pois a maioria dos sujeitos pesquisados percebe as violências e as repudia, mas é essencial capacitar os profissionais para intervirem e buscarem sua superação, com conhecimentos e sobre o tipo de intervenção adequado para o despertar da sensibilidade moral.

\section{REFERÊNCIAS}

BAUMAN, Z. Modernidade líquida. Rio de Janeiro: Jorge Zahar, 2001.

BOGDAN, R. C.; BIKLEN, S. K. Investigação qualitativa em educação. Porto Editora, 1994.

BRASIL. Ministério da Educação. Parâmetros curriculares nacionais: apresentação dos temas transversais: ética. 3 ed. Brasília: A Secretaria, 2001. 
CALIL, J. A. B. C. Concepção e implementação das regras na escola: a visão de equipes gestoras de escolas públicas de uma cidade do interior paulista. 2013. 221f. Dissertação (Mestrado em Educação). Campinas, São Paulo. 2013.

CECARRELLI, P. R. PATRICIO, C. J. Bullying e pós-modernidade: uma relação intrínseca. Revista Polêmica. v.12, n.3. 2013.

CUNHA, D. A. S. B. O discurso sóciomoral de professoras de pré-escola. In: 23a Reunião Anual da ANPED (Associação Nacional dos Pesquisadores em Educação), 2000, Caxambu.

DEVRIES, R.; ZAN, B. A ética na educação infantil: o ambiente sócio-moral na escola. Tradução: Fátima Murad. Porto Alegre: Artmed, 1998.

DIAS, T. O; SCHWARTZ, C. B; LISBOA, C. S. M. Comportamentos agressivos no contexto escolar. In: BORSA, J. C; BANDEIRA, D. R. (org) Comportamento agressivo na infância: da teoria à prática. 1. ed. São Paulo: Casa do Psicólogo, 2014, p. 223-237.

MENIN, M. S. de S. Valores na escola. Educação e Pesquisa, São Paulo, v. 28, n. 1, p. 91-100, jan./jun. 2002. https://doi.org/10.1590/S1517-97022002000100006

PAVANELI, Camila Fernanda Dias. Clima escolar: percepções de alunos, professores e gestores de escolas estaduais do Ensino Fundamental II. 155p. Dissertação de Mestrado Acadêmico - Instituto de Biociências, Letras e Ciências Exatas - Universidade Estadual Paulista (IBILCE/UNESP), São José do Rio Preto/SP, 2018.

PIAGET, J. O juízo moral na criança. São Paulo: Summus, 1932/1994.

SHIMIZU, A. M. As representações sociais de moral de professoras das quatro primeiras séries do ensino de 1o grau. Marília; 1998. Dissertação (Mestrado) - Unesp.

TOGNETTA, L. R. P. Vencer o bullying escolar: o desafio de quem se responsabiliza por educar moralmente. In: Tognetta, L. R. P., Vinha, T. P. É possível superar a violência na escola? São Paulo: Editora Brasil. Faculdade de Educação da Unicamp, 2012. p. 98-115.

TOGNETTA, L. R. P.; MARTINEZ, J. M. A.; DAUD, R. P. Respeito é bom e eu gosto: O valor do respeito. Americana: Adonis, 2017.

TOGNETTA, L. R. P. Bullying: quem tem medo? Americana: Adonis, 2015.

VINHA, T. P. O educador e a moralidade infantil: uma visão construtivista. Campinas, SP: Mercado de letras; São Paulo: Fapesp, 2000. Coleção Educação e Psicologia em Debate. 